\title{
PERENDAMAN GIGI PERMANEN MANUSIA DALAM MINYAK KELAPA MURNI (VIRGIN COCONUT OIL) TERHADAP PERUBAHAN WARNA GIGI PERMANEN MANUSIA
}

\author{
Lucia Yauri, Ellis Mirawati, Khoirunnisa Ilham
}

\begin{abstract}
ABSTRAK
Memutihkan gigi adalah upaya dalam menjadikan gigi lebih putih dari warna sebelumnya baik yang mengalami diskolorasi ekstrinsik maupun intrinsik. Masyarakat sering memanfaatkan bahan alami dibandingkan bahan kimiawi untuk memutihkan gigi karena dianggap lebih murah, aman, dan kemudahan dalam memperolehnya. Pada penelitian ini bahan pemutih gigi alami yang digunakan adalah virgin coconut oil. Minyak kelapa murni memiliki senyawa utama berupa asam laurat dengan persentase tinggi yang dapat membuat gigi menjadi putih. Penelitian ini bertujuan untuk mengetahui perubahan warna gigi setelah perendaman dalam minyak kelapa murni konsentrasi $100 \%$, digunakan rancangan eksperimen laboratorium pre-post test desain kelompok menggunakan 24 sampel gigi premolar post-ekstraksi. Masing-masing 4 kelompok perendaman yang terdiri dari 6 gigi direndam dalam minyak kelapa murni konsentrasi 100\% dalam waktu yang berbeda selama 1 hari, 2 hari, 3 hari, dan 4 hari. Warna gigi diukur perubahannya sebelum dan setelah perendaman menggunakan alat shade guide vitapan. Data dianalisis dengan uji one way anova. Dari hasil penelitian didapatkan kelompok $C$ (perendaman selama 3 hari) memperoleh ratarata perubahan skor paling besar dan kelompok $A$ (perendaman selama 1 hari) memperoleh ratarata perubahan skor warna gigi paling kecil. Didapatkan hasil data analisis nilai Sig. 0,041 $(P<\alpha$ $(0,05)$, artinya warna gigi mengalami perubahan signifikan menjadi lebih putih setelah perendaman dalam minyak kelapa murni.
\end{abstract}

Kata Kunci: Gigi Permanen, Minyak kelapa murni (Virgin coconut oil), perubahan warna gigi.

\section{PENDAHULUAN}

Warna gigi adalah suatu hal penting bagi setiap orang dalam menghasilkan senyum indah yang dapat menambah rasa percaya diri. Setiap individu memiliki karakteristik warna beragam pada email dan dentin giginya. Salah satu cara yang biasa dilakukan untuk menjadikan gigi lebih terang dan putih adalah dengan melakukan bleaching atau pemutihan gigi dengan bahan kimiawi. (Joiner, dkk, 2008)

Akan tetapi, karena besarnya biaya yang dikeluarkan untuk melakukan bleaching dan banyaknya penderita yang sensitif setelah perlakuan sehingga banyak penelitian yang dilakukan untuk mencari bahan alternatif lain yang lebih murah dan aman untuk digunakan sebagai bahan bleaching. Masyarakat sering memanfaatkan bahan alami karena dianggap lebih murah, aman, dan mudah untuk diperoleh dalam kehidupan sehari-hari daripada bahan kimiawi. $\mathrm{NaClO}$, SPB, dan H2O2 adalah macam bahan pemutih gigi yang telah digunakan dimana H202 adalah bahan aktif yang biasa digunakan untuk membuat gigi menjadi putih. Sementara itu, konsentrasi H2O2 telah ditemukan pada komposisi rendah pada makanan, minuman, buahbuahan, tanaman, dan bakteri. (Joiner, dkk, 2008)

Virgin coconut oil adalah bahan olahan alami dan tradisional yang bersumber dari tanaman buah kelapa yang memiliki khasiat dalam membuat gigi menjadi putih. (Aziz, dkk, 2017)

Syedah Klien Zahra Hussain (2004) adalah seorang ahli holistik di Amerika Serikat yang memberikan suatu cara praktis dan alami dalam memutihkan gigi dengan menggunakan minyak virgin coconut oil.

Tanaman kelapa di seluruh dunia memiliki banyak manfaat bagi kehidupan manusia, semua bagiannya dapat 
dimanfaatkan dimulai dari akar, batang, pelepah, daun, bunga dan buahnya. Oleh karena itu, kelapa sering disebut juga sebagai pohon kehidupan. Indonesia adalah negara tropis yang mempunyai banyak pulau dan termasuk negara penghasil kelapa terbaik di dunia, pada umumnya kelapa tumbuh dikawasan pantai. Tanaman kelapa dapat dijumpai hampis disetiap provinsi di perkebunan rakyat Indonesia. Salah satu bahan olahan alami dari buah kelapa yang saat ini banyak mendapatkan perhatian adalah virgin coconut oil. Bahan olahan ini berupa minyak kelapa hasil pemisahan dari santan yang dilakukan secara tradisional, merupakan produk olahan dari daging kelapa berbentuk larutan cair dan jernih serta tidak berasa dengan bau khas kelapa. Membuat minyak kelapa murni tidak menggunakan biaya yang banyak karena bahan baku yang digunakan relatif murah dan mudah untuk didapatkan dalam kehidupan sehari-hari, selain itu kualitas dari minyak kelapa murni ini lebih baik dari minyak kelapa kopra. (Aziz, dkk, 2017)

Dengan berdasarkan latar belakang tersebut peneliti akan melakukan penelitian dengan menggunakan minyak kelapa murni sebagai bahan pemutih gigi alternatif yang aman, murah, dan mudah diperoleh dalam kehidupan sehari - hari.

\section{METODE PENELITIAN}

Jenis penelitian yang digunakan dalam penelitian ini adalah eksperimental laboratorium dengan rancangan penelitian pre-post test desain kelompok. Tempat penelitian di Laboratorium Keperawatan Gigi Poltekkes Kemenkes Makassar dimulai dari bulan April hingga bulan Mei. Penelitian ini menggunakan sampel gigi premolar postekstraksi yang telah memenuhi kriteria inklusi dan ekslusi. Sampel untuk setiap kelompok adalah 6 dan jumlah sampel dari 4 kelompok adalah 24 sampel. Dalam penelitian ini menggunakan metode analisis data uji one way anova.

\section{HASIL PENELITIAN}

Dari penelitian yang dilakukan, didapatkan hasil sebagai berikut :

Tabel 1. Hasil Pengukuran Rerata Warna Gigi Kelompok A,B,C,D Sebelum dan Setelah Perendaman Dalam Virgin Coconut Oil dalam waktu yang berbeda

\begin{tabular}{|c|c|c|c|c|}
\hline \multirow{2}{*}{$\begin{array}{c}\text { SAMPEL } \\
\text { KELOMPOK A }\end{array}$} & \multicolumn{2}{|c|}{$\begin{array}{c}\text { SEBELUM } \\
\text { PERENDAMAN VCO }\end{array}$} & \multicolumn{2}{c|}{ VETELAH PERENDAMAN } \\
\cline { 2 - 5 } & WARNA GIGI & SKOR & WARNA GIGI & SKOR \\
\hline 1 & B4 & 13 & B3 & 11 \\
\hline 2 & D4 & 8 & B3 & 11 \\
\hline 3 & D4 & 8 & D3 & 10 \\
\hline 4 & B4 & 13 & B3 & 11 \\
\hline 5 & C2 & 7 & C1 & 6 \\
\hline 6 & D4 & 8 & D2 & 4 \\
\hline Rerata & & 9,50 & & 8,83 \\
\hline SD & \multicolumn{4}{|l}{} \\
\hline $\begin{array}{l}\text { SAMPEL } \\
\text { KELOMPOK B }\end{array}$ & 2,74 & & 3,06 \\
\hline
\end{tabular}




\begin{tabular}{|c|c|c|c|c|}
\hline \multirow{2}{*}{$\begin{array}{c}\text { SAMPEL } \\
\text { KELOMPOK A }\end{array}$} & \multicolumn{2}{|c|}{$\begin{array}{c}\text { SEBELUM } \\
\text { PERENDAMAN VCO }\end{array}$} & \multicolumn{2}{|c|}{$\begin{array}{c}\text { SETELAH PERENDAMAN } \\
\text { VCO }\end{array}$} \\
\hline & WARNA GIGI & SKOR & WARNA GIGI & SKOR \\
\hline 7 & B3 & 11 & B2 & 3 \\
\hline 8 & A4 & 15 & $\mathrm{~A} 3,5$ & 12 \\
\hline 9 & B3 & 11 & B2 & 3 \\
\hline 10 & A4 & 15 & $\mathrm{~A} 2$ & 5 \\
\hline 11 & D3 & 10 & $\mathrm{~A} 2$ & 5 \\
\hline 12 & $\mathrm{~B} 2$ & 3 & $\mathrm{~B} 2$ & 3 \\
\hline Rerata & & 10,83 & & 5,17 \\
\hline SD & & 4,40 & & 3,49 \\
\hline \multicolumn{5}{|l|}{$\begin{array}{c}\text { SAMPEL } \\
\text { KELOMPOK C }\end{array}$} \\
\hline 13 & $\mathrm{C} 4$ & 16 & $\mathrm{C} 2$ & 7 \\
\hline 14 & A4 & 15 & $\mathrm{~A} 3,5$ & 12 \\
\hline 15 & A4 & 15 & A4 & 15 \\
\hline 16 & B4 & 13 & $\mathrm{~B} 2$ & 3 \\
\hline 17 & B4 & 13 & $\mathrm{~B} 2$ & 3 \\
\hline 18 & D4 & 8 & $\mathrm{~B} 2$ & 3 \\
\hline Rerata & & 13,33 & & 7,17 \\
\hline SD & & 2,88 & & 5,23 \\
\hline \multicolumn{5}{|l|}{$\begin{array}{c}\text { SAMPEL } \\
\text { KELOMPOK D }\end{array}$} \\
\hline 19 & D4 & 8 & $\mathrm{D} 2$ & 4 \\
\hline 20 & A4 & 15 & A3,5 & 12 \\
\hline 21 & B4 & 13 & A3 & 9 \\
\hline 22 & B3 & 11 & $\mathrm{~B} 2$ & 3 \\
\hline 23 & B4 & 13 & $\mathrm{~A} 2$ & 5 \\
\hline 24 & $\mathrm{C} 2$ & 7 & $\mathrm{C} 1$ & 6 \\
\hline Rerata & & 11,17 & & 6,50 \\
\hline SD & & 3,13 & & 3,39 \\
\hline
\end{tabular}

Pada tabel 1 dapat dilihat bahwa rata-rata perubahan warna pada kelompok $A$ sebelum perendaman adalah 9,50 dengan standar deviasi 2,74. Setelah perendaman, nilai rata-rata menurun menjadi 8,83 dengan standar deviasi 3,06. Pada kelompok B sebelum perendaman adalah 10,83 dengan standar deviasi 4,40. Setelah perendaman, skor rata-rata menurun menjadi 5,17 dengan standar deviasi 3,49. Pada kelompok C skor sebelum perendaman adalah 13,33 dengan standar deviasi 2,88. Setelah perendaman, skor rerata menurun menjadi 7,17 dengan standar deviasi 5,23. Pada kelompok D sebelum perendaman adalah 11,17 dengan standar deviasi 3,13. Setelah perendaman, nilai rata-rata menurun menjadi 6,50 dengan standar deviasi 3,39. Penurunan rata-rata skor pada setiap kelompok adalah tanda bahwa terjadi perubahan warna pada gigi setelah perlakuan perendaman gigi dalam virgin coconut oil $100 \%$. 
Tabel 2. Analisis Data Deskriptif

\begin{tabular}{|c|c|c|c|}
\hline Kelompok & $\mathrm{N}$ & Rata-rata & Deviasi Standar \\
\hline Kelompok A & 6 & 0.67 & 2.66 \\
\hline Kelompok B & 6 & 5.67 & 3.72 \\
\hline Kelompok C & 6 & 6.17 & 4.17 \\
\hline Kelompok D & 6 & 4.67 & 2.80 \\
\hline
\end{tabular}

Dari tabel 2 rerata skor perubahan warna gigi setiap kelompok berdasarkan lama perendaman yang berbeda dalam virgin coconut oil $100 \%$, dapat dilihat bahwa kelompok C (perendaman selama 3 hari) memperoleh rata-rata perubahan skor warna gigi paling besar dan kelompok $A$ (perendaman selama 1 hari) memperoleh rata-rata perubahan skor warna gigi paling kecil.

Tabel 3. Uji Anova dan Signifikansi Data

\begin{tabular}{|l|c|c|c|c|c|}
\hline \multicolumn{7}{|c|}{ ANOVA } \\
\hline & Sum of squares & Df & Mean Square & F & Sig. \\
\hline Between Groups & 113.663 & 3 & 37.888 & 3.305 & .041 \\
\hline Within Groups & 229.295 & 20 & 11.465 & & \\
\hline Total & 342.958 & 23 & & & \\
\hline
\end{tabular}

Dari tabel 3 hasil uji anova dapat dilihat nilai Sig. $=0.041$. Karena nilai Sig. $=$ $0.041<\alpha=0,05$ maka memberikan kesimpulan untuk menerima $\mathrm{H}_{1}$ dan menolah $H_{0}$. Dengan demikian, ada perubahan warna pada gigi permanen manusia yang telah diskolorasi dengan kopi setelah perendaman

\section{PEMBAHASAN}

Penelitian ini menggunakan sampel gigi premolar post-ekstraksi yang telah dibersihkan dan dikeringkan dalam suhu ruangan. Untuk mendapatkan pewarnaan ekstrinsik, sampel gigi direndam selama 14 hari ke dalam larutan kopi dengan penggantian larutan kopi setiap 24 jam sekali hingga terjadi diskolorasi ekstrinsik pada gigi. dalam virgin coconut oil konsentrasi 100\% dengan waktu yang berbeda yaitu selama satu hari, dua hari, tiga hari, dan empat hari. Dimana perendaman selama 3 hari memberikan perubahan skor warna gigi paling besar.

Kopi adalah minuman familiar dan merupakan senyawa pembentuk warna yang paling kuat dalam mempengaruhi warna gigi dibandingkan dengan minuman lainnya seperti teh dan cola karena kaya akan bioaktif seperti nikotin dan kafein. ${ }^{14}$ Adapun virgin coconut oil yang digunakan dalam penelitian ini adalah yang dibuat sendiri oleh peneliti menggunakan $5 \mathrm{~kg}$ kelapa tua segar 
yang diparut dan ditambahkan air 4 liter lalu diperas, kemudian didapatkan santan kental yang selanjutnya didiamkan selama 36 jam sehingga terbentuk 3 bagian yang terdiri dari minyak kelapa murni $100 \%$, blondo, dan air. Dalam pembuatan ini, minyak kelapa murni yang dihasilkan sebanyak $\pm 480 \mathrm{ml}$.

Proses dalam membuat gigi menjadi putih dilakukan dengan merendam tiap sampel gigi dalam virgin coconut oil 100 \% pada waktu yang berbeda, dimana tiap kelompok terdiri dari 6 sampel gigi. Untuk kelompok A perendalam selama 1 hari, kelompok B perendaman selama 2 hari, kelompok $\mathrm{C}$ perendaman selama 3 hari, dan kelompok $D$ perendaman selama 4 hari. Untuk pengukuran warna gigi menggunakan alat shade guide vitapan. Gigi diukur dibawah sinar matahari dengan memperhatikan karakteristik persamaan warna antara tiap sampel gigi dengan hue pada shade guide.

Pada penelitian ini, hasil pengukuran warna gigi sebelum dan setelah perendaman dalam virgin coconut oil $100 \%$ selama 1 hari, 2 hari, 3 hari, dan 4 hari menunjukkan hasil nilai Sig. $=0.014$ sehingga nilai Sig. $P<\alpha(0.05)$. Sehingga, disimpulkan ada perubahan warna yang signifikan pada gigi permanen manusia yang telah diskolorasi dengan kopi setelah perendaman dalam virgin coconut oil konsentrasi $100 \%$ dengan waktu yang berbeda yaitu selama 1 hari, 2 hari, 3 hari, dan 4 hari.

Terlihat perubahan warna gigi menjadi lebih putih dengan penurunan skor pada tiap warna gigi setelah perendaman dalam virgin coconut oil. Pada kelompok $A$ rerata nilai sebelum perendaman adalah 9,50 dengan standar deviasi 2,74. Setelah perendaman, nilai rerata menurun menjadi 8,83 dengan standar deviasi 3,06. Pada kelompok B sebelum perendaman adalah 10,83 dengan standar deviasi 4,40. Setelah perendaman, nilai rerata menurun menjadi 5,17 dengan standar deviasi 3,49. Pada kelompok $\mathrm{C}$ sebelum perendaman adalah 13,33 dengan standar deviasi 2,88. Setelah perendaman, nilai rerata menurun menjadi 7,17 dengan standar deviasi 5,23. Pada kelompok $\mathrm{D}$ sebelum perendaman adalah 11,17 dengan standar deviasi 3,13. Setelah perendaman, nilai rerata menurun menjadi 6,50 dengan standar deviasi 3,39. Sehingga waktu perendaman paling efektif adalah pada kelompok $\mathrm{C}$ dengan lama perendaman selama 3 hari. Perubahan warna pada gigi juga dapat dipengaruhi oleh adanya variabel penggangu tiap kelompok yang berbeda seperti diskolorasi intrinsik, ketebalan email gigi yang berbeda, $\mathrm{pH}$, suhu dan temperatur.

Virgin coconut oil dengan kandungan asam lauratnya yang tinggi memiliki kemampuan dalam memutihkan gigi. Kandungan asam laurat dalam minyak kelapa murni sebanyak $44 \%-53 \% .^{5,13}$ Virgin coconut oil didalam tubuh dapat membentuk produk turunan minyak kelapa murni berupa monolaurin yang bekerja dalam melakukan perlawanan terhadap mikroorganisme secara efektif. Virgin coconut oil mengandung asam laurat yang dapat membentuk zat sabun laurat yang berperan dalam mengurangi perlekatan pelikel dan penimbunan plak pada gigi, selain itu virgin coconut oil juga bertindak sebagai agen pembersih rongga mulut dan dapat menghilangkan stain.

Hasil penelitian sebelumnya yang telah dilakukan oleh Gloria Ganapragasan, (2017) yang melakukan penelitian tentang 
perubahan warna gigi permanen manusia setelah perendaman dalam virgin coconut oil $100 \%$ selama 1 hari, 2 hari, dan 3 hari menggunakan VCO yang sudah tersedia dipasaran dengan merek Parachute. Hasil penelitian ini menjelaskan bahwa VCO paling efektif memutihkan gigi pada perendaman selama 3 hari dibandingkan dengan perendaman selama 1 atau 2 hari dan menyimpulkan bahwa semakin lama waktu perendaman maka semakin putih warna gigi yang dihasilkan.

Virgin coconut oil adalah bahan alami olahan buah kelapa yang dapat membuat gigi menjadi putih dan mudah untuk dibuat sendiri. Pada penelitian ini, skor perubahan rata-rata warna gigi sebelum dan setelah perendaman tiap kelompok berdasarkan lama perendaman dalam virgin coconut oil kandungan $100 \%$ mengalami nilai penurunan rata-rata skor dari kelompok $A$ yaitu 0,67 , kelompok $B$ menjadi 5,67 hingga ke kelompok $C$ dengan nilai 6.17 dan mulai menurun rata-rata penurunan skornya pada kelompok D menjadi 4,67. Sehingga kelompok C perendaman selama 3 hari memperoleh rata-rata perubahan skor warna gigi paling besar dan kelompok $A$ perendaman selama 1 hari memperoleh ratarata perubahan skor warna gigi paling kecil. Oleh karena itu, peneliti menyimpulkan bahwa waktu perendaman paling efektif adalah selama 3 hari.

\section{KESIMPULAN}

Dapat dilihat bahwa ada perubahan warna pada gigi permanen manusia yang telah diskolorasi dengan kopi setelah perendaman dalam virgin coconut oil dengan waktu yang berbeda yaitu selama 1 hari, 2 hari, 3 hari, dan 4 hari. Perubahan warna gigi menjadi putih ditandai dengan penurunan rerata skor pada semua kelompok setelah perendaman dalam virgin coconut oil konsentrasi $100 \%$. Cara menggunakan virgin coconut oil untuk memutihkan gigi dan menjaga kesehatan rongga mulut individu dikenal sebagai oil pulling dengan cara mengoleskan virgin coconut oil pada gigi dan berkumur selama 10-15 menit.

\section{SARAN}

Diharapkan minyak kelapa murni dapat diproduksi sebagai obat kumur yang dapat memutihkan gigi.

\section{DAFTAR PUSTAKA}

Joiner A, Hopkinson I, Deng Y, Westland S 2008, 'A Review of tooth colour and whiteness'. Journal Science Direct, Vol.36s, hh.s2-s7.

Joiner, A 2006, 'The Bleaching of Teeth : A Review of the Literature'. Journal Of Dentistry, Vol 34, hh.412-19.

Hendari R. 'Pemutihan Gigi (ToothWhitening) Pada Gigi Yang Mengalami Pewarnaan'. Semarang. 2009 ; Vol. XLIV, hh.65-78.

Aziz T, Olga Y, dan Puspita AS 2017, 'Pembuatan Virgin Coconut Oil (VCO) Dengan Metode Penggaraman'. Jurnal Teknik Kimia Palembang, Vol.23(2), hh.129-136.

Kablian A, Ramamurthy J 2016, 'Efficacy of oil infused toothpaste against oil pulling: a study'. Journal of pharmaceutical, biological and chemical, Vol.7(6), hh.1-5

Tempo.co. 2016, Gunakan minyak kelapa untuk putihkan gigi, diakses tanggal 22 Januari 2020, https://gaya.tempo.co/read/508375/ gunakan-minyak-kelapa-untukputihkan-gigi/full\&view=ok

Itjingningsih, 2012, Anatomi Gigi, EGC, Jakarta.

Machfoedz, I 2008, Menjaga Kesehatan Gigi dan Mulut Anak-anak dan lbu Hamil, Fitramaya, Yogyakarta.

Tarigan R, Tarigan G 2012, Perawatan Pulpa Gigi (Endodonti), EGC, Jakarta.

Astuti, P 2016, Cara Hebat Bisnis Dan Usaha Berkebun Kelapa, Forest Publishing, Jawa Barat. 
Setyamidjaja, D 1991, Bertanam Kelapa Budidaya dan Pengolahannya, Kanisius, Yogyakarta.

Nursuci, S 2012, Teknologi Budidaya Tanaman Kelapa, CV Amalia Book, Bandung.

Hanafiah AWS, Maria EW, Kartini NO 2011, 'Pembuatan, Pemurnian Dan Stabilitas Virgin Coconut Oil (VCO) Bertanda Radiodium-13'1. Jurnal Sains dan Teknologi Nuklir Indonesia, Batam, Vol.XII(2), hh.7584.

Wibi, P 2007, 'Pengaruh Penambahan Virgin Coconut Oil (VCO) Pada Perasan Buah Makuto Dewo (Phaleria Macrocarpa(Scheff.) Boerl) Pada Mencit Betina Terinduksi Parasetamol: Kajian Terhadap Efek Hepatoprotektif', Skripsi Fakultas Farmasi Universitas Sanata Dharma, Yogyakarta.

Barlina R, Torar, D 2018, 'Diversifikasi Produk Virgin Coconut Oil (VCO). Balai Penelitian Tanaman Kelapa
Dan Palma Lain', Vol.12, hh.7-8 ; 2018

Kumar V, Shanbag, 2017, 'Oil Pulling for Maintaining Oral Hygiene - A Review', Journal Of Traditional And Complementary Medicine, Vol.7(1), hh.106-9.

Adrian, N 2012, 'Penentuan Warna Gigi Insisif Sentral Dan Caninus Dengan Spektrofotometer', Thesis FKG Program Pendidikan Kedokteran Gigi Spesialis Departemen Prostodonsia, Jakarta.

Febriani, L 2016, 'Pengaruh Bleaching Dengan Ekstrak Buah Belimbing Manis (Averrhoa Carambola) Terhadap Derajat Perubahan Warna Gigi', Fakultas Kedokteran dan IImu Kesehatan, Yogyakarta.

Ganapragasan, G 2017, 'Perubahan Warna Gigi Permanen Manusia Setelah Perendaman Dalam Virgin Coconut Oil ( Minyak Kelapa Murni) Konsentrasi 100\%'. Skripsi FKG Universitas Sumatera Utara, Medan. 